\title{
FLORA DA SERRA DO CIPÓ, MINAS GERAIS: CELASTRACEAE SENSU LATO ${ }^{1}$
}

\author{
MILTON GROPPO \& CÍNTIA ERBERT
}

\author{
Departamento de Biologia, - Faculdade de Filosofia, Ciências e Letras de Ribeirão Preto, \\ Universidade de São Paulo. Av. Bandeirantes, 3900 - CEP 14040-901, \\ Ribeirão Preto, São Paulo, Brasil
}

\begin{abstract}
Flora of the Serra do Cipó, Minas Gerais: Celastraceae sensu lato). The study of the family Celastraceae is a part of the project of "Flora of Serra do Cipó, Minas Gerais, Brazil". In its most recent delimitation, Celastraceae sensu lato encompass the Hippocrateaceae, a group already addressed in a previous survey to the Serra do Cipó, the later with three genera (Cheiloclinium, Peritassa and Tontelea), with four species. To these taxa are now summoned the species of Celastraceae sensu stricto, with the genus Maytenus (seven species), and Plenckia (one species), besides two species representing two genera (Pristimera and Salacia) of traditional Hippocrateaceae collected after the publication of the Hippocrateaceae survey. As a summary, Celastraceae sensu lato is represented in Serra do Cipó by seven genera and 14 species. Keys are presented to the genera and species of Celastraceae sensu lato, as well as descriptions, illustrations and comments on the geographic distribution, phenology and variability of the species of Celastraceae sensu stricto (previously untreated). Comments and an updated list of exsiccate of "Hippocrateaceae" are also provided. Additionally, we propose the synonymy of Maytenus salicifolia Reissek under M. gonoclada Mart.
\end{abstract}

Key words: Hippocrateaceae, floristics, campo rupestre vegetation, Espinhaço Range.

Resumo - (Flora da Serra do Cipó, Minas Gerais: Celastraceae sensu lato). O estudo da família Celastraceae é parte do levantamento da "Flora da Serra do Cipó", Minas Gerais, Brasil. Em sua delimitação mais recente, as Celastraceae sensu lato englobam as Hippocrateaceae, já tratadas em levantamento anterior para a Serra Cipó, esta última com três gêneros (Cheiloclinium, Peritassa e Tontelea) e quatro espécies. A estes gêneros e espécies de Hippocrateceae são somadas agora as espécies de Celastraceae sensu stricto, com o gênero Maytenus (sete espécies) e Plenckia, com uma espécie, além de duas espécies de dois gêneros (Pristimera e Salacia) das tradicionais Hippocrateaceae coletadas após a publicação do levantamento. Com isso, para a Serra do Cipó são registrados sete gêneros e 14 espécies de Celastraceae sensu lato. São apresentadas chaves para os gêneros e espécies de Celastraceae sensu lato e descrições e ilustrações das Celastraceae sensu stricto (não tratadas anteriormente), além de comentários sobre sua distribuição geográfica, fenologia e variabilidade. Comentários e uma lista atualizada de exsicatas das "Hippocrateaceae" são também apresentados. Adicionalmente, é proposta a sinonímia de Maytenus salicifolia Reissek sob Maytenus gonoclada Mart.

Palavras-chave: Hippocrateaceae, florística, campo rupestre, Cadeia do Espinhaço.

\section{Celastraceae s.l.}

Árvores, arbustos, subarbustos ou lianas. Folhas simples, alternas ou opostas, estípulas pequenas, inconspícuas, decíduas, ou ausentes. Inflorescências terminais ou axilares racemosas, cimosas ou fasciculadas. Flores bissexuadas ou unissexuadas (plantas monoicas ou dioicas), actinomorfas, (2-)4-5-meras, geralmente pouco chamativas; sépalas livres ou pouco conatas na base; pétalas imbricadas; estames isostêmones (polistêmones em Plagiopteron), alternipétalos, inseridos abaixo ou sobre as bordas de um disco intraestaminal carnoso, raro livres do disco; anteras bitecas, deiscência longitudinal, transversal ou oblíqua; ovário súpero, livre ou variadamente envolvido pelo disco, 2-5-carpelar, 2-5-locular; óvulos por lóculo 1-2(-14), sobrepostos ou colaterais, eretos ou pêndulos, placentação axial. Fruto cápsula (septicida), drupa ou sâmara; sementes geralmente ariladas, ou aladas e neste caso sem arilo.

A circunscrição das Celastraceae atuais (aqui chamadas de Celastraceae sensu lato) engloba as Hippocrateaceae (cf. APG 2009), após estudos filogenéticos baseados em dados morfológicos e moleculares (Simmons \& Hedin 1999, Simmons et al. 2000, 2001). Tradicionalmente, as Hippocrateaceae diferem das Celastraceae sensu stricto (como na delimitação utilizada por Cronquist 1981) principalmente por características do androceu, composto geralmente por três estames de deiscência variável, mas quase nunca introrsa (v. 4-5 em Celastraceae s.s. de deiscência introrsa, cf. Lombardi \& Gracie 2004) e pelo disco extraestaminal ( $v$. estames inseridos sobre o disco ou disco intraestaminal, cf. Simmons 2004, em Celastraceae s.s.). Além disso, em muitos gêneros de Hippocrateaceae (como em

\footnotetext{
${ }^{1}$ Trabalho realizado segundo o planejamento apresentado em Giulietti et al. (1987).
} 
Cheiloclinum e Tontelea, que ocorrem na Serra do Cipó) a deiscência das anteras é por meio de fendas transversais (v. longitudinais em Celastraceae s.s.).

Segundo Simmons et al. (2001), as Celastraceae s.l. possuiriam 55 a 94 gêneros e 8501300 espécies, dependendo do conceito de autores como Hallé (1986), Thorne (1992), Heywood (1993) e Mabberley (1993). Thorne \& Reveal (2007) chegam a contar 98 gêneros (com 1210 espécies). Estes números refletem o pouco conhecimento taxonômico do grupo e uma história de controvérsias sobre a delimitação de vários de seus gêneros. Lombardi et al. (2015) referem para o Brasil 19 gêneros e 141 espécies, com espécies novas sido reconhecidas recentemente (Groppo et al. 2014, Biral \& Lombardi 2013, 2014).

No tratamento sobre as Hippocrateaceae da Serra do Cipó, Furlan \& Arrais (1989) reconheceram três gêneros (Cheiloclinium, Peritassa e Tontelea) com uma espécie cada. Coletas posteriores de Peritassa flaviflora A.C.Sm., Pristimera celastroides (Kunth) A.C.Sm. e Salacia elliptica (Mart.ex Schult.) G.Don. tornaram as Hippocrateaceae representadas por cinco gêneros e seis espécies na Serra do Cipó. Somandose as Celastraceae sensu stricto com os gêneros
Maytenus (com seis espécies) e Plenckia (uma espécie) ocorrem, finalmente, sete gêneros e 14 espécies de Celastraceae sensu lato na Flora da Serra do Cipó.

As chaves de identificação para os gêneros ocorrentes na Serra do Cipó apresentam todos os táxons de Celastraceae s. l.; entretanto são descritos apenas os gêneros e espécies de Celastraceae sensu stricto (Maytenus e Plenckia). Descrições e dados mais detalhados sobre as Hippocrateaceae da Serra do Cipó devem ser consultados em Furlan \& Arrais (1989), além de Lombardi \& Lara (2003) no que se refere a descrição e ilustrações de Peritassa flaviflora, Pristimera celastroides e Salacia elliptica. Uma lista atualizada do material disponível de Hippocrateaceae coletado na Serra do Cipó é apresentada junto de cada espécie aqui tratada.

Bibliografia básica - Reissek (1861), Lundell (1939), Loesener (1942), Edwin \& Hou (1975), Heywood (1993), Simmons \& Hedin (1999), Mitchell (2004), Ferreira et al. (2003), , Groppo \& Pirani (2003), Carvalho-Okano (1995, 2000, 2005), Simmons et al. (2000, 2001), Simmons (2004), Carvalho-Okano \& Leitão-Filho (2005), Groppo (2005, 2008, 2009), Viana \& Vieira (2007), Coughenour et al. (2010).

\section{Chave para os gêneros}

1. Estames 3(5); disco nectarífero extraestaminal; folhas (sub)opostas ou alternas; fruto drupa ou esquizocarpo com três mericarpos deiscentes; árvores, lianas ou arbustos ("Hippocrateaceae").

2. Fruto esquizocarpo com três mericarpos deiscentes por fissuras medianas

2'. Fruto drupa.

3. Deiscência das anteras por fendas transversais.

4. Disco nectarífero cobrindo totalmente ovário e estilete, apenas os 3 estigmas aparentes

4'. Disco nectarífero curto tubular e livre, mais comumente ligado aos lobos do ovário por prolongamentos deste, não cobrindo totalmente ovário e estilete, estigma 3-lobado no ápice de estilete curto 5. Pristimera Deiscência das anteras longitudinal ou por fendas oblíquas confluentes no ápice.

5. Anteras com deiscência longitudinal

5 . Anteras deiscentes por fendas oblíquas confluentes no ápice

1'. Estames 5; disco intraestaminal; folhas alternas; fruto cápsula ou sâmara (para as espécies conhecidas da Serra do Cipó); árvores, arbustos ou subarbustos ("Celastraceae s.s").

6. Fruto cápsula; sementes ariladas

2. Maytenus

6 '. Fruto sâmara; sementes sem arilo

4. Plenckia

\section{Cheiloclinium Miers}

\subsection{Cheiloclinium cognatum (Miers) A.C.Sm.,} Brittonia 3(3): 529. 1940.

Material examinado: Itambé do Mato Dentro, distrito de Santana do Rio Preto (Cabeça de Boi), APA do Parque Nacional da Serra do Cipó, Mata do Cachoeirão, 1925'54,7"S, 4325'58,3"W, 13.III.2008, M.F. Santos 261 \& $H$. Serafim, fl. (BHCB, HRCB, SPF); Santana do Riacho, UCAT, Barragem estrada Riachinho, 25.II.1985, P.M. Andrade \& M.A. Lopes 8749, fr. (BHCB, SPF); idem, km 104 da Rodovia Belo Horizonte - Conceição do Mato Dentro, vale do córrego Véu da Noiva, 12.I.1981, L. Rossi et al. CFSC 6998, fl. (BHCB, SP, SPF).
Espécie distribuída pela América Central (Costa Rica e Panamá) e América do Sul (Colômbia, Venezuela, Guiana, Suriname, Guiana Francesa, Peru, Bolívia e Brasil, em vários estados brasileiros (Acre, Amapá, Amazonas Rondônia, Roraima, Pará, Tocantins, Maranhão, Piauí, Pernambuco, Bahia, Mato Grosso, Goiás, Distrito Federal, Espírito Santo, Rio de Janeiro e São Paulo, nos domínios da Amazônia, Cerrado, Mata Atlântica e Pantanal (Lombardi \& Lara 2003; Lombardi et al. 2015), em áreas florestadas. $\mathrm{Na}$ Serra do Cipó ocorre em matas ciliares, nas bordas ou no seu interior. Coletadas com flores em janeiro e março, com frutos (uma coleta) em fevereiro. 
Das espécies de "Hippocrateaceae" da Serra do Cipó, Cheiloclinium cognatum é a única arbórea de grande porte, podem atingir $13 \mathrm{~m}$ (Santos $261 \& \mathrm{H}$. Serafim), as outras sendo lianas, arbustos ou subarbustos.

llustrações em Furlan \& Arrais (1989) e Lombardi \& Lara (2003).

\section{Maytenus Molina}

Árvores, arbustos ou subarbustos, glabros ou pubescentes. Folhas alternas, dísticas, subsésseis a pecioladas, glabras a pubescentes, às vezes cerosas, margem crenada, dentada, dentado-espinhosa ou inteira; estípulas pequenas, geralmente cedo decíduas. Inflorescências axilares, fascículos, cimeiras ou tirsos, raro paniculiformes. Flores (4-)5-meras, diclinas ou funcionalmente monoclinas, isostêmones; sépalas unidas; corola branco-esverdeada, pétalas patentes; estames alternipétalos, filetes cilíndricos a achatados; gineceu 2(-3)-carpelar, 2(-3)-locular; óvulos por lóculo 2, placentação axial; disco intra-estaminal carnoso, inteiro a levemente crenado. Fruto cápsula loculicida, bivalvar (valvas reflexas), orbicular, angular ou piriforme, raramente cápsula tardiamente deiscente sem valvas reflexas (em Maytenus megalocarpa), estilete às vezes persistente. Sementes 1-3 (até 4 em M. megalocarpa), envoltas por um arilo branco-leitoso.

Maytenus Molina sensu lato (incluindo Gymnosporia (Wight \& Arn.) Hook. f.) tem sido tradicionalmente tratado com um gênero de ca. 300 espécies distribuído nos (sub)trópicos do Velho e do Novo Mundo (McKenna et al. 2011). Entretanto, análises filogenéticas atuais tem demonstrado que Maytenus (incluindo os gêneros extra-brasileiros Moya Griseb. e Tricerma Liebm. como sinônimos) deveria ser aplicado apenas às espécies Neotropicais (Maytenus sensu stricto, cf. Simmons et al. 2008, McKenna et al. 2011), mas mesmo esta circunscrição não leva à monofilia do gênero, dado o posicionamento de alguns gêneros próximos, como Fraunhofera Mart. e Plenckia Reissek (McKenna et al. 2011, Groppo et al. 2014), incluídos no clado de Maytenus. Novos estudos com base em dados moleculares ainda estão em progresso e poderão no futuro propor uma melhor delimitação para o gênero.

No Brasil cerca de 50 espécies são conhecidas, e espécies novas tem sido descritas recentemente (Groppo et al. 2014, Biral \& Lombardi 2014), ocorrendo em vários tipos de vegetação, incluindo a Floresta Amazônica, a Mata Atlântica (incluindo restingas) caatinga, cerrado e campos rupestres (Groppo 2008, Lombardi \& Groppo 2010, Lombardi et al. 2015). Na Serra do Cipó são conhecidas sete espécies. A taxonomia das espécies é problemática, sendo muitas vezes delimitadas com base em características vegetativas (Steyermark 1988, Groppo et al. 2014), especialmente o aspecto do ápice dos ramos novos e margem foliar (Groppo 2008).

Os epítetos específicos de algumas espécies que aparecem na Flora brasiliensis (Reissek 1861) foram corrigidos (como em Maytenus aquifolia e $M$. gonoclada) para concordar com o nome genérico, que é feminino.

Chave para as espécies

1. Lâmia foliar espinescente; nervação semi-craspedódroma

2.1. M. aquifolia

$1^{\prime}$. Lâmina foliar de margem inteira, crenada, dentada ou ondulada, mas não espinescente

nervação broquidódroma ou eucamptódroma.

2. Lâminas foliares estreitas, 7,5-10 vezes mais compridas do que largas, as margens inteiras ou raro com 1-2 pequenos dentes na porção distal

2 '. Lâminas foliares no máximo 4 vezes mais compridas do que largas, as margens crenadas, crenado-denteadas, crenuladas ou apenas irregulares.

3. Ápice dos ramos pubérulos, 4-angulares no ápice ....

3'. Plantas glabras; ápice dos ramos novos cilíndricos, ou 4-angulares

4. Lâmina foliar crenulada ou apenas ondulada.

5. Inflorescências em tirsos multifloros, frequentemente ramificados na base, congestos ou alongados, até ca. $1,5 \mathrm{~cm}$ compr.; ápice dos ramos novos 4-angulares, os ângulos carenados até (sub)alados; lâmina foliar no mínimo ca. $3 x$ mais comprida que larga $(5,5-$ $15,2 \times 1,7-4,7 \mathrm{~cm})$, elíptica a estreitamente elíptica, crenulada próximo ao ápice 2.2. M. brasiliensis

5'. Flores em fascículos; ápice dos ramos cilíndricos sem carenas; lâmina foliar no máximo $2 x$ mais comprida do que larga $(4,0-6,1 \times 2,0-4,0 \mathrm{~cm})$, oboval (raro elíptica), margem levemente crenulada nos $2 / 3$ distais ou apenas irregular

2.7. M. rupestris

âmina foliar manifestadamente crenada ou crenada-denteadas, em toda a extensão ou apenas nos $2 / 3$ distais.

6. Flores em fascículos; lâmina foliar com nervuras secundárias formando ângulos de $30^{\circ}$ $35^{\circ}$ (chegando a $10^{\circ}$ no ápice) em relação à nervura principal

6.' Inflorescências em tirsos multifloros, até ca. $1,5 \mathrm{~cm}$ compr.; nervuras secundárias formando ângulos de $38^{\circ}-75^{\circ}$ em relação à nervura principal.

7. Ápice dos ramos novos 4-angulares, os ângulos carenados até (sub) alados, frutos apiculados.

$7^{\prime}$ Ápice dos ramos novos cilíndricos, com ou sem carenas, mas não 4-angulares; frutos não apiculados, ocasionalmente com o estilete persistente 
2.1. Maytenus aquifolia Mart., Flora 24(2): 4. 1841.

Fig. $1 \mathrm{~A}$

Arbustos ou arvoretas 1,5-2,5 m alt., glabros; ápice dos ramos novos cilíndrico-complanados, sem carenas ou alas. Folhas pecioladas, patentes, glabras; lâmina 7,0-18,0 cm compr., 2,5-6,5 cm larg., in sicco verde clara ou acinzentada em ambas as faces, coriácea, elíptica ou oblonga, ápice geralmente agudo, mucronado, margem espinescente, os espinhos formados pelo ápice das nervuras secundárias, base aguda ou obtusa, nervação semi-craspedódroma, nervuras secundárias proeminentes em ambas as faces, em ângulo de $50^{\circ}-70^{\circ}$ em relação á nervura central; pecíolo 4,0-9,0 $\mathrm{mm}$. Inflorescências fasciculadas. Flores 5-meras, ca. 7,0 mm diâm.; sépalas ovais, (sub)ciliadas; pétalas ovais, ca. $4,0 \mathrm{~mm}$ compr. Cápsula elipsóide ou obovóide, ca. $1,0 \mathrm{~cm}$ compr., castanho-amarelada quando madura, não apiculada.

Material examinado: Santana do Riacho: APA Morro da Pedreira ( $2^{\circ}$ grupo), subida pela pousada da Pedreira, grande afloramento calcário na base da serra, área próxima à prática de rapel, $19^{\circ} 18^{\prime} 48,5^{\prime \prime} \mathrm{S}, 4^{\circ} 36^{\prime} 39,7^{\prime \prime} \mathrm{W}, 865 \mathrm{~m}$, 17.VI.2007, M. Groppo et al. 1445, estéril (SPF, SPFR); idem: distrito de Cardeal Motta, Morro da Pedreira ( $2^{\circ}$ grupo), afloramentos calcários na base da serra, fazenda Canto da Serra, 22.VII.1993, J.R. Pirani et al. CFSC 13286, estéril (SPF, SPFR).

Material adicional examinado: Paraná: Leópolis: 26.X.1999, O.C. Pavão \& J.A. Ferreira s.n., fr. (FUEL, SP); Londrina, Associação dos Funcionários Públicos de Londrina, 27.VIII.1993, L.H. Soares-Silva 327, fl. (SPFR, UEL); Sapopema, 11.X.1997, C. Medri et al. 474, fr. (FUEL, SP). Rio Grande do Sul: Pareci, IX.1938, B. Rambo 3184, fl. (SP). São Paulo: Monte Alegre-Amparo: 24.VIII.1943, M. Kuhlmann 954, fr. (SP); Socorro, bacia do rio Jaboticabal (afluente do rio do Peixe), bairro Jaboticabal, sítio Beija-Flor, propriedade do sr. Alfred Erbert, 2235'S, 4631'W, 22.VII.2007, M. Groppo 1459, estéril (SPFR); Vinhedo, 23.IX.1977, R. Monteiro 6502, fl. (SP, UEC).

Maytenus aquifolia ocorre no Brasil, na região Sudeste (Minas Gerais, Rio de Janeiro e São Paulo), além da Região Sul, no domínio da Mata Atlântica, principalmente na Floresta Estacional Semidecidual, ou ainda em matas ciliares e de galeria ou em afloramentos rochosos (Lombardi et al. 2015); ocorre predominantemente na submata. Há também registros para o Paraguai, no Alto Paraná (e.g. L.C. Stutz 1796, G). Na Serra do Cipó foi coletada na APA Morro da Pedreira, em mata seca sobre calcário. Não foi encontrada fértil nos materiais examinados da Serra do Cipó.

Maytenus aquifolia é facilmente reconhecida na área pelas folhas espinescentes, os espinhos rígidos formados pelas terminações das nervuras secundárias. É a única espécie pertencente a $M$. sect. Oxyphylla Loes. (sensu Carvalho-Okano 1992) que ocorre na Serra do Cipó (as outras pertenceriam à seção típica), caracterizada pela folhas espinescentes ou com um único espinho apical. Entretanto, os resultados de Groppo et al. (2014) demonstraram que estas duas seções não correspondem a grupos monofiléticos. É conhecida vulgarmente como "espinheira-santa" (Pirani et al. CFSC13286). nome dado também a outra espécie do gênero, $M$. ilicifolia Mart. ex Reissek (Carvalho-Okano \& Leitão-Filho 2005), da qual se diferencia pelas folhas com espinhos em toda a margem foliar ( $v$. concentrados no ápice da lâmina ou ainda com apenas um espinho apical em $M$. ilicifolia) e pelo ápice dos ramos novos sem estrias longitudinais ( $v$. com quatro estrias longitudinais). Além disso, a distribuição de $M$. ilicifolia é mais ao sul quando comparada com $M$. aquifolia - Brasil, nos estados de Mato Grosso do Sul, São Paulo e todos os estados da Região Sul, mais Chile, Paraguai, Uruguai e Bolívia (Groppo et al. 2014)

A descrição das inflorescências, flores e frutos foram baseadas em coletas de outras localidades.

2.2. Maytenus brasiliensis Mart., Flora 24(2), Beibl. 87-88. 1841.

Maytenus ligustrina Reissek, in Mart., FI. bras. 11(1): 25. 1861.

Fig. 1 B-C

Arbustos, arvoretas a árvores 2,0-8,0 m alt., glabros; ápice dos ramos novos complanados, 4angulares, os ângulos carenados até (sub) alados. Folhas, pecioladas, patentes; lâmina $5,5-15,2 \mathrm{~cm}$ compr., $1,7-4,7 \mathrm{~cm}$ larg., in sicco verde clara ou acinzentada em ambas as faces, cartácea a coriácea, elíptica a estreitamente elíptica, ápice acuminado ou agudo, margem crenada a crenulada, base aguda ou atenuada, nervação broquidódroma, nervuras secundárias proeminentes em ambas as faces, em ângulo de $55^{\circ}-75^{\circ}$ em relação à nervura central; pecíolo 2,0-5,0mm compr. Inflorescências em tirsos multifloros, até ca. $1,5 \mathrm{~cm}$ compr. Flores 5-meras, ca. 5,0 mm diâm.; sépalas ovais, (sub)ciliadas; pétalas ovais, ca. 2,5 mm compr. Cápsula obovóide, castanha a alaranjada quando madura, 0,9-1,2 cm compr., apiculada, apículo ca. $1 \mathrm{~mm}$ compr.

Material examinado: Minas Gerais, Serra do Cipó, Santana do Riacho: km 113 ao longo da rodovia Belo Horizonte - Conceição do Mato Dentro, margens do córrego Chapéu de Sol, sem data, F. Barros CFSC 1345, fr. (SP, SPFR); idem: ao longo da rodovia Belo Horizonte Conceição do Mato Dentro, vale do córrego Chapéu de Sol, 05.X.1980, I. Cordeiro \& J.R. Pirani CFSC 6518, fl., fr. (SP, SPFR); idem: estrada Santana do Riacho-Lapinha, $19^{\circ} 08^{\prime} \mathrm{S}$ $43^{\circ} 41$ 'W, 1150 m, 5.III.1998, R.C. Forzza et al. 772, fr. (K, SPF); idem: km 107 ao longo da rodovia Belo Horizonte Conceição do Mato Dentro, 4.X.1981, J.R. Pirani et al. CFSC 7461, fl., fr. (SP, SPFR); idem: mata de galeria do córrego Chapéu de Sol, atrás da pensão, 25.VI.1988, D.C. Zappi CFSC 1117, fr. (SP, SPFR).

Material adicional examinado: "Brasil-Ilheos et Rio de Janeiro, 1838, C.F.P. Martius 627 (NY, lectótipo de Maytenus brasiliensis Mart., isolectótipos MO, RB). Rio de Janeiro, 1824 , C. Gaudichaud-Beaupré 819 (síntipo original de Maytenus ligustrina Reissek, $\mathrm{B}$, destruído, foto $\mathrm{F}$ negativo 13296). São Paulo: São Miguel Arcanjo, $24^{\circ} 03^{\prime} 14^{\prime \prime} S$, $47^{\circ} 59^{\prime} 32^{\prime \prime} \mathrm{W}, 22 . I V .2002$, S. Bortoleto et al. 91, fr. (ESA, SPF). 
Flora da Serra do Cipó, Minas Gerais: Celastraceae sensu lato
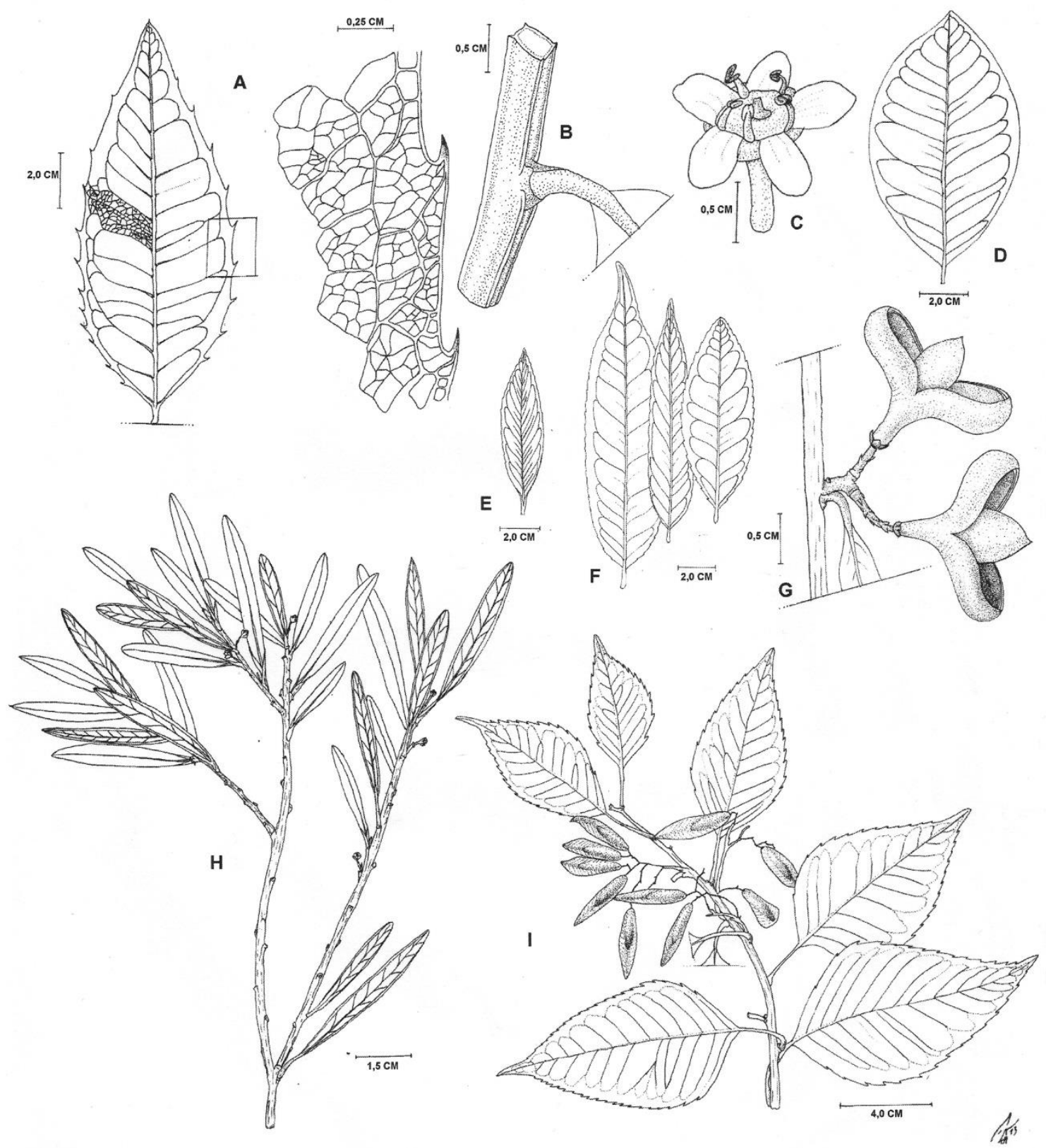

Fig. 1 - Maytenus aquifolia: A. Folha, à esquerda detalhe da nervação. Maytenus brasiliensis: B. Detalhe do ápice do ramo $4-$ angular, subalado; C. Flor. Maytenus erythroxyla: D. Folha. Maytenus floribunda: E. Folha. Maytenus gonoclada: F. Folhas de três diferentes indivíduos; G. Fruto aberto. Maytenus rupestris: H. Ramo com flores. Plenckia populnea: I. Ramo com frutos. (A. Pirani et al. CFSC 13286; B. Cordeiro \& Pirani CFSC 6518; C. Pirani et al. CFSC 7461; D. Groppo et al. 1500; E. Groppo et al. 1453; F. da esquerda para a direita Groppo et al. 645, Campos \& Roque CFSC 13336, Groppo et al. 1474; G. Groppo et al. 1403; H. Joly et al. CFSC 4607; I. Groppo et al. 635). 
Maytenus brasiliensis ocorre no Brasil, desde o litoral do sul da Bahia, Espírito Santo, norte do Rio de Janeiro, Minas Gerais e São Paulo, em áreas de Floresta Estacional Semidecidual e Floresta Ombrófila Densa, no domínio da Mata Atlântica (Groppo 2008). A espécie é também citada para Pernambuco (Lombardi et al. 2015). Na Serra do Cipó foi coletada em áreas de mata semidecídua ou ciliar, com flores em setembro e outubro e frutos em março, junho, setembro-outubro.

Maytenus brasiliensis é semelhante a Maytenus gonoclada Mart., principalmente pelas folhas crenadas ou crenuladas e pelas inflorescências em tirsos (isto é, não fasciculadas). Difere entretanto pelo ápice dos ramos novos 4-angulares, os ângulos carenados até (sub) alados (vs. cilíndricos ou carenados, mas não 4-angulares, em $M$. gonoclada) e pelos frutos apiculados (vs não apiculados em $M$. gonoclada).

Maytenus ligustrina Reissek, citada para a flora de São Paulo por Carvalho-Okano (2005) foi recentemente incluída na sinonímia de $M$. brasiliensis por Joffilly \& Vieira (2006).

2.3. Maytenus erythroxylon Reissek in Mart. FI. bras. 11(1): 21.1861.

Fig. 1 D

Arbustos a árvores, 2,0-7,0 $\mathrm{m}$ alt., glabros; ápice dos ramos novos cilíndrico, sem carenas ou alas. Folhas pecioladas, patentes; lâmina 4,0-6,1 cm compr., 2,0-4,0 cm larg., in sicco acastanhada na face adaxial, mais pálida na abaxial, coriácea a fortemente coriácea, oboval, raro elíptica, ápice obtuso, agudo ou truncado, geralmente emarginado, margem levemente crenulada nos $2 / 3$ distais ou apenas ondulada, base obtusa ou arredondada, nervação broquidódroma, nervuras secundárias não proeminentes, imersas no mesofilo, em ângulo de $60^{\circ}-75^{\circ}$ em relação à nervura central; pecíolo 3,0-7,0 $\mathrm{mm}$ compr. Inflorescências fasciculadas. Flores 5-meras, ca. 5,0 mm diâm.; sépalas ovais, (sub)ciliadas; pétalas ovais, ca. $2,5 \mathrm{~mm}$ compr. Cápsula piriforme, ca. $0,9 \mathrm{~cm}$ compr., não apiculada.

Material examinado: Minas Gerais, Serra do Cipó, Santana do Riacho: $19^{\circ} 18^{\prime} 48,5^{\prime \prime} \mathrm{S}, 43^{\circ} 36^{\prime} 39,7^{\prime \prime} \mathrm{W}, 1318 \mathrm{~m}$, 24.IX.2007, M. Groppo et al.1500, estéril (BHCB, SPF, SPFR); APA Morro da Pedreira (2॰ grupo), 22.VII.1993, J.R. Pirani et al. CFSC 13289, fl. (SPF, SPFR).

Material adicional examinado: Minas Gerais: Matozinhos, 31.X.1996, J.A. Lombardi 1445, fr. (BHCB); Nova Ponte, EPDA-JACOB/CEMIG, 25.IX.1996, E. TameirãoNeto 2121, fr. (BHCB); Lagoa Santa, APA Carste de Lagoa Santa, 18.X.1995, A.E. Brina \& L.V. Costa s.n., fr. (BHCB 32716); idem, 3.VIII.1995, A.E Brina \& L.V Costa s.n., fl. (BHCB 32762). Pernambuco: sem localidade, s.d., G. Gardner 1143, fl. (SP, isolectótipo de M. erythroxyla Reissek). São Paulo: Bauru, Jardim Botânico de Bauru, 13.IX.1996, M.H.O. Pinheiro 128, estéril (BHCB, SPFR).
Maytenus erythroxylon ocorre no Brasil, nos estados do Maranhão, Piauí, Ceará, Rio Grande do Norte, Pernambuco, Alagoas e Bahia, no domínio da Caatinga (na caatinga sensu stricto) e em áreas no domínio da Mata Atlântica, em restingas (Lombardi et al. 2015). A espécie tem sido também coletada em Minas Gerais, em áreas de afloramento calcário (ver material adicional examinado logo acima), sendo estas as primeiras referências na literatura para este tipo de ambiente. Na Serra do Cipó foi coletada apenas na APA Morro da Pedreira, em solo sobre afloramento calcário, em uma população quase homogênea (espécie dominante em alguns pontos) com flores em junho.

Maytenus erythroxylon é, segundo CarvalhoOkano (2005), caracterizada pelas folhas essencialmente inteiras (ou com a margem levemente crenulada nos 2/3 distais ou ainda apenas onduladas, como verificado aqui), pelas inflorescências em fascículos e pelo ápice dos ramos novos com numerosas lenticelas. Entretanto, apesar do materialtipo (Gardner 1143, citado acima) possuir o ápice dos ramos lenticelados, vários materiais coletados fora das restingas dos estados nordestinos não apresentam lenticelas ou estas estão presentes quantidades variáveis. Estudos mais aprofundados desta espécie são necessários para estabelecer melhor seus limites de distribuição e características morfológicas distintivas.

2.4. Maytenus evonymoides Reissek in Mart, FI. bras. 11(1): 11.1861.

Arbusto 3,0 $\mathrm{m}$ alt., ápice dos ramos novos pubérulos, 4-angulares, com carenas nos ângulos. Folhas pecioladas, patentes, glabras na face adaxial, pubérulas nas nervuras da face abaxial, principalmente próximo à base da lâmina; lâmina 2,2$5,0 \mathrm{~cm}$ compr., 0,9-1,7cm larg., in sicco esverdeada em ambas as faces, membranácea, ápice agudo ou acuminado, margem crenada, base aguda, nervação broquidódroma, nervuras secundárias proeminentes, em ângulo de $50^{\circ}-65^{\circ}$ em relação à nervura central; pecíolo até 2,0mm compr. Inflorescências fasciculadas. Flores 5-meras, ca. 5,0 mm diâm.; sépalas ovais, (sub)ciliadas; pétalas ovais, ca. $3,0 \mathrm{~mm}$ compr. Cápsula orbicular, ca. $0,7 \mathrm{~cm}$ compr., não apiculada.

Material examinado: Minas Gerais, Santana do Pirapama, Serra do Cipó, Capela de São José, Trilha da Senhorinha, caminho a Congonhas do Norte, $18^{\circ} 54^{\prime} 33,21^{\prime \prime S}$, 434' 44,59'w, 1232 m, 24.IX.2009, D.C. Zappi et al. 2512, fr. (SPF).

Material adicional examinado: Paraná: Piraquara, Serra Piramirim, 15.XII.1995, J.M. Silva \& J.M. Cruz 1586, fr. (MBM, SPF). São Paulo: São Paulo, Parque do Estado, 28.VIII.1951, W. Hoehne s.n., fl. (MBM, SPF13635, SPFR, SPSF, UEC); São Paulo, Santo Amaro, I.1985, F.M. Felipe s.n., fr. (MBM, SPF 47183, UEC). 
Maytenus evonymoides ocorre nos estados do Centro Oeste (Distrito Federal, Goiás e Mato Grosso do Sul), Sudeste (Minas Gerais, Rio de Janeiro e São Paulo) e estados da Região Sul (Lombardi et al., 2015), além de Bolívia e no Paraguai. Ocorre no domínio do Cerrado e da Mata Atlântica, em campos de altitude, em matas ciliares ou de galeria, na Floresta Estacional Semidecidual e Decidual, na Floresta Ombrófila e na Floresta Ombrófila Mista (Mata de Araucária) (Lombardi et al. 2015), sendo geralmente espécie de submata. Na Serra do Cipó é conhecida de apenas uma coleta, de Santana do Pirapama, em área de mata perturbada, com flores e frutos imaturos em novembro.

As características das flores foram descritas com base em materiais coletados em outras localidades. Ilustrações podem ser encontradas em Carvalho-Okano (2005)

2.5. Maytenus floribunda Reissek in Mart. Fl. bras. 11(1): 16. 1861.

Fig. $1 \mathrm{E}$

Arvoretas a árvores, 2,0-8,0m alt, glabras; ápice dos ramos novos cilíndricos, carenados. Folhas pecioladas, patentes; lâmina 5,5-8,5cm compr., 2,3$5,5 \mathrm{~cm}$ larg., in sicco verde-clara prateada em ambas as faces, coriácea, ápice agudo ou acuminado, margem crenado-denteada geralmente apenas nos $2 / 3$ distais, base cuneada ou aguda, nervação broquidódroma ou eucamptódroma, nervuras secundárias proeminentes, em ângulos de $30^{\circ}-35^{\circ}$ (chegando a $10^{\circ}$ no ápice) em relação à nervura principal, pecíolo $5,0-8,8 \mathrm{~mm}$ compr. Inflorescências fasciculadas. Flores 5-meras, ca. 6,0 mm diâm.; sépalas ovais, ciliadas; pétalas ovais, ca. $2,5 \mathrm{~mm}$ compr. Cápsula orbicular, amarelada, ca. $0,8 \mathrm{~cm}$ compr., não apiculada.

Material examinado: Minas Gerais, Santana do Pirapama, Serra do Cipó, Rio das Pedras, na proximidade da ponte de Rio das Pedras, $19^{\circ} 01^{\prime} 28,88^{\prime \prime S}, 43^{\circ} 45^{\prime} 02^{\prime \prime}$, 663 $\mathrm{m}$, 17.XI.2009, D.C. Zappi et al. 2407, fr. (RB, SPF); idem, acesso por Inhame, fazendas ao norte da Fazenda Inhame, $18^{\circ} 55^{\prime} 45,83^{\prime \prime}$, 434' $28,17^{\prime \prime} \mathrm{W}, 775 \mathrm{~m}, 29 . X 1.2009$, W. Miliken et al. 4179, fr. (SPF); Santana do Riacho: Cardeal Motta, morro da Pedreira ( $2^{\circ}$ grupo), Fazenda Canto da Serra, 22.VII.1993, M.T.V.A. Campos et al. CFSC 13293 , estéril (SPF); idem: grande afloramento calcário na base da

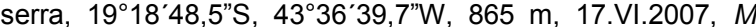
Groppo et al. 1447, estéril (SPF, SPFR); idem: morro com vegetação decídua no topo e semi-decídua na base, 19'18'18,4"S, 4336'47,9'W, 935 m, 17.VI.2007, M. Groppo et al. 1453, estéril (SPFR); idem: mata decídua sobre calcário, 19¹8'48,5"S, 4336'39,7”W, 1318 m, 24.IX.2007, M. Groppo et al. 1498, estéril (SPF, SPFR).

Material adicional examinado: São Paulo: Ribeirão Preto, Fazenda Boa Esperança, próximo ao distrito de Bonfim Paulista, 28.III.2001, O. Kotchetkoff-Henriques \& M.Sandrini 358, fl. (BHCB, SPF, SPFR); idem: reserva 136, 1.II.2002, $O$. Kotchetkoff-Henriques \& Lucas 359, fr. (BHCH, SPFR).

Maytenus floribunda é encontrada em vários estados brasileiros, em todas as macrorregiões (Norte,
Nordeste, Sul, Sudeste e Centro-Oeste), no domínio da Amazônia, Cerrado e Mata Atlântica, em florestas ciliares ou de galeria, Floresta de Terra Firme, Florestas Estacionais Semideciduais e Deciduais e na vegetação sobre afloramentos rochosos (Lombardi et al. 2015). Há referência também para a Guiana Francesa (Molino \& Sabatier 2427, MO). Na Serra do Cipó ocorre em matas de galeria e em áreas de matas decíduas, como na APA Morro da Pedreira, sobre rochas calcárias. Foi coletada com frutos em novembro.

Maytenus floribunda pode ser identificada pelas folhas verde-claras prateadas quando secas e pelas nervuras secundárias em ângulos agudos, de $30^{\circ}-35^{\circ}$ (chegando a $10^{\circ}$ no ápice) em relação à nervura principal, chegando a $10^{\circ}$ no ápice; com a margem crenada-denteada.

As características florais foram descritas com base em materiais coletados em outros locais.

2.6. Maytenus gonoclada Mart., Flora 24(2): 89. 1841.

Maytenus robusta Reissek in Mart., FI. bras. 11(1): 15. 1861

Maytenus salicifolia Reissek in Mart., FI. bras. 11(1): 10.1861, syn. nov.

Fig. $1 \mathrm{~F}, \mathrm{G}$

Arbustos, arvoretas ou árvores, 2,0-6,0m alt., glabros; ápice dos ramos novos cilíndricos ou carenados, mas não 4-angulares. Folhas pecioladas, patentes; lâmina 4,0-16,5cm compr., 1,7-4,8cm larg., in sicco verde clara a acinzentada em ambas as faces, cartácea a coriácea, elíptica, oboval, oblonga ou lanceolada, ápice agudo ou acuminado, margem crenada, base aguda ou obtusa, nervação broquidódroma, nervuras secundárias proeminentes, em ângulos de $38^{\circ}-65^{\circ} \mathrm{em}$ relação à nervura principal; pecíolo 3,0-13,0mm compr. Inflorescências em tirsos multifloros, até ca. $1,5 \mathrm{~cm}$ compr, freqüentemente ramificados na base. Flores 5-meras, ca. $6,0 \mathrm{~mm}$ diâm, sépalas obovais, (sub)ciliadas, pétalas obovais, ca. 2,0 $\mathrm{mm}$ compr. Cápsula orbicular ou piriforme, ca. 11,0$17,0 \mathrm{~mm}$ compr., amarelada ou castanho-avermelhada quando madura, não apiculada, ocasionalmente com o estilete persistente.

Material examinado: Minas Gerais, Serra do Cipó, Conceição do Mato Dentro: trilha para a cachoeira da Farofa, próximo à sede do IBAMA, $19^{\circ} 22^{\prime 2} 26^{\prime \prime} \mathrm{S}, 43^{\circ} 35^{\prime} 52,9^{\prime \prime} \mathrm{W}, 838 \mathrm{~m}$, 22.IX.2007, M. Groppo et al. 1472, estéril (SPFR); idem: trilha para a cachoeira da Farofa, próximo à sede do IBAMA, 19²2'26"S, 43॰35'52,9"W, 838 m, 22.IX.2007, M. Groppo et al. 1473, estéril (SPFR); idem: trilha para a cachoeira da Farofa, próximo à sede do IBAMA, 19²2'26"S, 4335'52,9"W, 838 m, 22.IX.2007, M.Groppo et al. 1474, estéril (HRCB, MBM, SPF, SPFR); idem: Parque Natural Municipal do Ribeirão do Campo, $19^{\circ} 05^{\prime} 36,8^{\prime \prime} S$, $43^{\circ} 35^{\prime} 31,2^{\prime \prime W}$, 13.IX.2002, R.C. Mota et al. 1668, fr. (BHCB, SPF); idem: $19^{\circ} 04^{\prime} 25,7^{\prime \prime} \mathrm{S}, 4^{\circ} 36^{\prime} 54,6^{\prime \prime} \mathrm{W}, 13 . \mathrm{IX} .2002$, R.C. Mota et al. 1669, fl. (BHCB); Itambé do Mato Dentro, Distrito de Santana do Rio Preto (Cabeça de Boi), APA Parque 
Nacional da Serra do Cipó, 24.X.2008, M.F. Santos 391 \& J.B.C.Marques, fl. (BHCB, SPF); Jaboticatubas: Colônia, 24.X.1974, G. Hatschbach \& L.F. Ferreira 35271, fl. (BHCB, MBM); Santana do Riacho: ca. $400 \mathrm{~m}$ antes da bifurcação entre Morro do Pilar e Conceição do Mato Dentro, capão de mata a W da rodovia, 10.VIII.1993, M.T.V.A. Campos \& N. Roque CFSC 13336, botões (SPF); idem: 21.IX.1993, M.T.V.A. Campos \& E.D.P. de Souza CFSC 13370, bt., fl. (SP, SPF, SPFR); idem: 29.VIII.1994, M.T.V.A. Campos \& J.M. Arcanjo CFSC 13787, bt. (SP, SPF); idem: córrego 3 Pontinhas, km 119 (novo) da rodovia Belo Horizonte Conceição do Mato Dentro; 1280 m, 23.XI.1990, A. Freire \& F.R.S. Pires 1559, fl., fr. (SPF, SPFR); idem: ca. $400 \mathrm{~m}$ antes da bifurcação Morro do Pilar - Conceição do Mato Dentro, 2.III.2001, M. Groppo et al. 645, fr. (F, K, MBM, NY, SPF, SPFR); idem: 2.III.2001, M. Groppo et al. 647, fr. (F, K, SPF, SPFR); idem: 2.III.2001, M. Groppo et al. 649, fr.. (F, K, SPF, SPFR); idem: ca. $400 \mathrm{~m}$ antes da bifurcação Morro do Pilar Conceição do Mato Dentro, MG-010, grande capão de mata do lado esquerdo da rodovia, sentido Santana do Riachobifurcação, 19॰12'53,8"S, 4330'39,0"W, 1349 m, 14.VI.2007, M. Groppo et al. 1403, fr. (MBM, RB, SP, SPF, SPFR); idem: 14.VI.2007, M.Groppo et al. 1404, fr. (HRCB, MBM, RB, SPF, SPFR); idem: ao longo da rodovia MG-010, trecho Santana do Riacho - Conceição do Mato Dentro, altura da pousada Chapéu de Sol, 19¹8'03,7"S, 43³6'04,1"W, $1070 \mathrm{~m}$, 16.VI.2007, M. Groppo et al. 1428, estéril (SPFR); idem: APA morro da Pedreira, $2^{\circ}$ grupo de afloramento calcário na base da serra, 1918'48,5"S, 4336'39,7"W, 1318 m, 24.IX.2007, M. Groppo et al. 1499, estéril (SPFR); idem: km 132 ao longo da Rodovia Belo Horizonte - Conceição do Mato Dentro, 18.XII.1979, J.R. Pirani et al. CFSC 5850, fr. (SP, SPFR); idem: rodovia Belo Horizonte - Conceição do Mato Dentro, mata ciliar do córrego Três Pontinhas, 25.IV.1992, J.R. Pirani et al. CFSC 12945, fr. (SPF, VIC).

Material adicional examinado: Brasilia meridionali, s.d., Sellow 325, fl. (NY, síntipo de Maytenus salicifolia Reissek); Brasilia, in silvis capoes prov.S.Pauli, 1817, C.F.P. Martius 301, fr. (M, holótipo de M. gonoclada); Brasilia meridionali, a S. Paulo ad meridiem, s.d., Sellow 150, fl. (B, destruído, foto $\mathrm{F}$, negativo 13315, tipo de Maytenus robusta

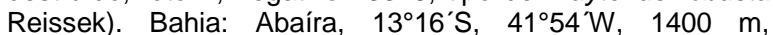
6.VII.1992, W. Ganev 619, fr. (SP, SPF); Rio de Contas, Pico das Almas, $13^{\circ} 32^{\prime} \mathrm{S}, 4^{\circ} 56^{\prime} \mathrm{W}, 1250 \mathrm{~m}, 14 . \mathrm{XI} .1988$, R.M. Harley et al. 26151, fl. (SP, SPF). Minas Gerais: Betim, Serra da Caveira, 13.IX.1945, L.O. Williams \& V. Assis 7500, fl. (SP); Grão-Mogol: 4252'30"S, 16³3'18”W, ca. $1000 \mathrm{~m}$, 5.I.1986, I. Cordeiro et al. CFCR 8883, fr. (SP, SPF); idem: $42^{\circ} 52^{\prime} 30^{\prime \prime} \mathrm{S}, 16^{\circ} 33^{\prime} 18^{\prime \prime W}$, ca. 1000 m, 5.XI.1987, J.R. Pirani et al. CFCR 11548, fl. (SP, SPF, UEC); Lagoa Santa: APA Carste de Lagoa Santa, s.d., A.E. Brina \& L.V. Costa s.n., fr. (BHCB).

Maytenus gonoclada ocorre em vários estados brasileiros, no Nordeste (Bahia) todos os estados da Região Sudeste e na região Sul (Paraná e Santa Catarina), no domínio do Cerrado e da Mata Atlântica, em matas ciliares e de galeria, nas Florestas Estacionais Semidecidual e Decidual, na Floresta Ombrófila Mista (Mata de Araucária), próximo a manguezais, em restingas e também sobre afloramentos rochosos (Lombardi et al. 2015). Também é referida para Goiás (Carvalho-Okano \& Leitão-Filho 2005) e Distrito Federal (Ferreira et al. 2003). Na Serra do Cipó foi coletada em áreas de mata, nas bordas ou no seu interior, com algumas coletas em áreas mais abertas como matas secas sobre solo calcário (APA Morro da Pedreira), em áreas pouco sombreadas pelas rochas. Flores de agosto a novembro, com frutos em vários meses do ano.

Maytenus gonoclada é uma espécie caracterizada pelas folhas crenadas, com inflorescências em tirsos de até $1,5 \mathrm{~cm}$ de comprimento, ocorrendo essencialmente em áreas de fisionomia florestada. A diferenciação desta espécie com outras de morfologia semelhante, como $M$. salicifolia Reissek e $M$. robusta Reissek feita por autores anteriores (e.g. Reissek 1861, CarvalhoOkano 2005) era feita pela observação dos ramos (cilíndricos ou angulosos), consistência da lâmina (membranáceas, cartáceas ou coriáceas) ou formato dos frutos (orbiculares ou piriformes). Entretanto, depois do exame do material-tipo dos táxons envolvidos (ver material adicional examinado) e de outras coleções, notou-se a intergradação destas características. Com isso, já havia sido proposta a sinonimização de $M$. robusta em $M$. gonoclada em Groppo (2009) e agora também de $M$. salicifolia sob M. gonoclada. A distribuição geográfica destes três táxons também era simpátrica.

2.7. Maytenus rupestris Pirani \& Carvalho-Okano, Novon 9: 95. 1999.

Fig. $1 \mathrm{H}$.

Arbustos ou arvoretas, $1,0-3,0 \mathrm{~m}$ alt., glabros; ápice dos ramos, 4-angulares, sem carenas ou alas. Folhas subsésseis, ascendentes; lâmina $3,0-8,0 \mathrm{~cm}$ compr., $0,4-0,8 \mathrm{~cm}$ larg., in sicco acinzentada ou glauca em ambas as faces ou levemente ocrácea na face adaxial, coriácea, estreitamente oblonga a estreitamente elíptica, ápice obtuso, às vezes agudo ou truncado, geralmente mucronado, margem inteira ou raro com até 2 pequenos dentes na porção distal, base atenuada e decurrente para o curto pecíolo, nervação broquidódroma, nervuras secundárias não proeminentes em ambas as faces, em ângulo de $50^{\circ}$ $65^{\circ} \mathrm{em}$ relação à nervura principal; pecíolo até $1,0 \mathrm{~mm}$ compr. Inflorescências em cimeiras reduzidas a 2-3(-4) flores, 6,0-14,0 mm compr. Flores 5-meras, ca. 5,0 mm diâm.; sépalas ovais, ciliadas; pétalas oblongas, ca. 3,0 mm compr. Cápsula elipsóide ou obovóide, ca. 1,0 $\mathrm{cm}$ compr., amarelada a alaranjada quando madura, apiculada, apículo ca. $1 \mathrm{~mm}$ compr.

Material examinado: Minas Gerais, Serra do Cipó, Conceição do Mato Dentro: Parque Natural Municipal do Ribeirão do Campo, $19^{\circ} 05^{\prime} 30,6^{\prime \prime} S, 43^{\circ} 34^{\prime} 10,8^{\prime \prime} \mathrm{W}, 13 . I X .203$, R.C. Mota et al. 2145, fl. (BHCB, SPF); Congonhas do Norte: Serra Talhada (setor NE da Serra do Cipó), 6,8km SW da estrada Congonhas do Norte - Gouveia, 1850'33,3"S, $43^{\circ} 45^{\prime} 32,1$ "W, $1200 \mathrm{~m}, 19.1 .2007$, J.R. Pirani et al. 5591, fr. (SPF, SPFR); Jaboticatubas: km 128 ao longo da rodovia Lagoa Santa-Conceição do Mato Dentro, 04.XI.1972, A.B. Joly CFSC 3691, fl. (SP, SPF, VIC); idem: km 129, 20.X.1973, A.B. Joly et al. CFSC 4607, fl. (SP, UEC); idem: km 117, 4.IX.1973, J. Semir et al. 4381, fl., fr. (SP, UEC); Santana do Riacho: km 123 (antigo 128), ao longo da rodovia Belo Horizonte - Conceição do Mato Dentro, 04.IX.1980, I. 
Cordeiro \& J.R. Pirani CFSC 6509, fl. (SP); idem: ribeirão Indequicé, cachoeira do Cornélio, perto da estrada da Usina, 5.X.1981, A. Furlan et al. CFSC 7506, fl. (K, NY, RB, SP, SPF, VIC, tipo); idem: ao longo da rodovia Lagoa Santa Conceição do Mato Dentro - Diamantina, 26.VII.1973, N.L. Menezes CFSC 4293, fr. (SP); idem: estrada da Usina, ribeirão Indequicé, próximo à cachoeira, 14.XI.1983, J.R Pirani \& L. Rossi CFSC 9215, fl., fr. (BHCB, G, SPF, UB, VIC); idem: km 111, vale do córrego Vitalino, 20.V.1989, J.R. Pirani CFSC 11449,fr. (CEPEC, F, MBM, SPF, U,VIC); idem: rodovia MG-010, Vale da Mãe D'Água, 19¹8'11"S, 4336'03"W, $1113 \mathrm{~m}, 4 . I I I .1998$, J.R. Pirani et al. 4201, fr. (BHCB, K, NY, SPF); idem: km 117 ao longo da rodovia Belo Horizonte - Conceição do Mato Dentro, córrego do Vitalino 3.XI.1978, M.S.F. Silvestre 192, fl., fr. (SP, SPF, SPFR); idem: $2 \mathrm{~km}$ acima da entrada para a estrada da Usina, 6.IX.1987, R. Simão CFSC 10427, fl. (SPF); idem: base da cachoeira da Farofa, $19^{\circ} 22^{\prime} 49^{\prime \prime S}, 43^{\circ} 34^{\prime} 37^{\prime \prime W}, 1010 \mathrm{~m}, 6 . \mathrm{VII} .2001$, V.C Souza et al. 25258, fl., fr. (ESA, SPFR); idem: distrito de São José da Cachoeira, trilha para a cachoeira Bonita, 1858'40"S, 4346'35"W, 680 m, 18.II.2007, V.C. Souza et al. 32619, fr. (ESA, SPFR); idem: ao longo da Rodovia Lagoa Santa - Conceição do Mato Dentro - Diamantina, 3.XI.1978, M.G.L. Wanderley 511, fl. (SP, SPF, SPFR); Santana do Riacho, APA Morro da Pedreira, Rodovia Belo Horizonte-
Conceição do Mato Dentro (MG 010), Alto do Palácio, ca.

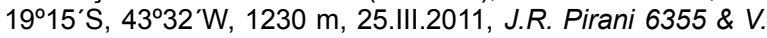
Augusto, fr. (SPF).

Maytenus rupestris é até agora conhecida apenas da Serra do Cipó, sendo provavelmente endêmica dessa região. Ocorre principalmente em campos rupestres, entre rochas ou suas fendas, também em margens de córregos e riachos, não sendo, porém, espécie de submata (Pirani \& CarvalhoOkano 1999). Floresce de setembro a novembro, frutos de novembro a março ou até maio.

Maytenus rupestris é distinta das outras espécies pelas suas folhas ascendentes e estreitas, de margem inteira ou com 1-2 dentes na porção distal, e pelas inflorescências reduzidas a cimeiras paucifloras. As folhas in sicco ficam acinzentadas ou glaucas em ambas as faces ou levemente ocráceas na face adaxial, provavelmente pela presença de uma camada de cera epicuticular.

llustrações adicionais em Pirani \& CarvalhoOkano (1999).

\section{Peritassa Miers}

Chave para as espécies

1. Pétalas 2,1-2,8 mm compr.; folhas geralmente alternas, mas às vezes subopostas ou opostas; arbustos ou subarbustos em áreas de cerrado

3.1. P. campestris

$1^{\prime}$. Pétalas 1,0-1,6 mm compr., folhas (sub)opostas; árvores de mata 3.2. P. flaviflora

3.1. Peritassa campestris (Cambes.) A.C. Sm., Brittonia 3(3): 514. 1940.

Material examinado: Santana do Riacho, Serra do Cipó, km 109 da Rodovia Belo Horizonte - Conceição do Mato Dentro, estrada da Usina Dr. Pacífico Mascarenhas, 5.X.1981, A. Furlan et al. CFSC7514, fl. (BHCB, HRCB, NY MBM, SP, SPF); idem, estrada entre a sede do IBAMA e a Cachoeira da Farofa, ca. $2,5 \mathrm{~km}$ da sede, próximo ao

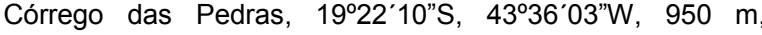
4.VII.2011, V.C. Souza et al. 25008, fl. (ESA, SPF).

Peritassa campestris ocorre no Brasil (Tocantins, Maranhão, Mato Grosso, Mato Grosso do Sul, Distrito Federal, Minas Gerais, Rio de Janeiro e São Paulo) e Paraguai (Lombardi \& Lara 2003; Lombardi et al. 2015), nos domínios do Cerrado e Mata Atlântica, em áreas de campos, cerrados e cerradões. Na Serra do Cipó ocorre em manchas de cerrado, sendo um arbusto ou subarbusto de até ca. $1,0 \mathrm{~m}$ de altura, com ramos eretos. Flores em novembro e julho.

llustrações em Furlan \& Arrais (1989) e Lombardi \& Lara (2003).
3.2. Peritassa flaviflora A.C.Sm., Brittonia 3(3): 507. 1940

Material examinado: Itambé do Mato Dentro, Distrito de Santana do Rio Preto (Cabeça de Boi), APA Parque Nacional da Serra do Cipó, $19^{\circ} 23^{\prime} 49,2^{\prime \prime}$, 4324'05,8'W, 24.VIII.2007, M.F. Santos 142 \& E.G.Martins, fl. (HRCB, SPF); idem, $19^{\circ} 23^{\prime} 53,9^{\prime \prime S}, 43^{\circ} 24^{\prime} 09,2^{\prime \prime} \mathrm{W}, 24 . \mathrm{VIII} .2007$, M.F. Santos 151 \& E.G.Martins, fl. (HRCB, SPF); idem, $19^{\circ} 23^{\prime} 46,9^{\prime \prime S}, 43^{\circ} 24^{\prime} 07,4^{\prime \prime}$, 15.XII.2007, M.F. Santos 352 \& L.M.Borges, fr. (HRCB, SPF).

Peritassa flaviflora ocorre em Minas Gerais, Rio de Janeiro e São Paulo (Lara \& Lombardi 2003), ocorrendo na Floresta Estacional Semidecidual, no Domínio da Mata Atlântica (Lombardi et al. 2015), em áreas de encosta ou na mata ciliar. Na Serra do Cipó foi coletada até o momento em Itambé do Mato Dentro, em bordas de mata e matas ripárias. Uma das coletas (Santos 352 \& Borges) cita a espécie como de sub-bosque. Segundo Lara \& Lombardi (2003), a espécie pode se apresentar na forma de árvore, arbusto ou ainda liana, mas na Serra do Cipó todas as coleções são de árvores, de 2,5 a 6,0 m de altura. 
Coletada com flores em agosto, com frutos em dezembro.

llustrações em Lombardi \& Lara (2003).

\section{Plenckia Reissek}

Árvores ou arbustos. Folhas alternas, pecioladas, margem serreada ou crenada; estípulas pequenas, escamiformes, decíduas. Inflorescências axilares, em tirsos ou panículas. Flores 5-meras, diclinas ou monoclinas, isostêmones; sépalas unidas, corola amarelada ou creme, pétalas patentes; estames alternipétalos, filetes cilíndricos; gineceu 2-carpelar, 2locular, ovário imerso no disco, óvulos por lóculo (1-)2, placentação axilar; disco intra-estaminal carnoso, inteiro. Fruto sâmara, oblonga. Sementes 1.

Gênero neotropical com seis espécies distribuídas no Brasil, Argentina e Paraguai (Lundell 1939), com novos registros na Bolívia. O gênero necessita de revisão taxonômica. Na Serra do Cipó ocorre Plenckia populnea Reissek.

4.1. Plenckia populnea Reissek in Mart., FI. bras. 11(1): 31. 1861.

Fig. 1 I

Árvores ou arvoretas, 2,0-9,0m alt., glabras; ápice dos ramos cilíndricos. Folhas espiraladas, pecioladas, pendentes; lâmina 3,5-11,2 cm compr., $1,2-5,9(-7,2) \mathrm{cm}$ larg., in sicco acastanhada em ambas as faces, cartácea ou membranácea, oval, largamente oval ou deltóide, raro elíptica, ápice agudo ou acuminado, geralmente apiculado, margem crenada ou serreada, base obtusa ou truncada, raro aguda, nervação eucamptódroma ou broquidódroma, nervuras secundárias proeminentes em ambas as faces, em ângulo de $57^{\circ}-70^{\circ}$ em relação à nervura principal; pecíolo 1,2-3,0(-3,5)cm compr. Inflorescências em tirsos multifloros, até ca. $6,0 \mathrm{~cm}$ compr. Flores ca. 3,0-4,0 mm diâm.; sépalas elípticas ou orbiculares; pétalas obovais ou orbiculares ca. 2 $\mathrm{mm}$ compr., ciliadas. Sâmara oblonga ou oblanceolada, 2,1-3,6cm compr., 0,4-1,0 cm larg.

Material examinado: Minas Gerais, Serra do Cipó, Jaboticatubas: trilha para a cachoeira da Farofa, próximo à sede do IBAMA, $19^{\circ} 22^{\prime} 46^{\prime \prime S}, 43^{\circ} 344^{\prime} 34,5^{\prime \prime}, 838 \mathrm{~m}$, 22.IX.2007, M. Groppo et al. 1462, fl. (K, SP, SPFR); Santana do Pirapama, Serra do Cipó, vilarejo Inhame, trilha para o topo da Serra a partir da porteira azul na estrada vilarejoFazenda Toucan-Cipó, 19.XI.2007, L.M. Borges et al. 260, fl. (K, MBM, SPF); idem, acesso pela Fazenda Inhame, Fazenda Toucan-Cipó, proximidades do estábulo, $19^{\circ} 00^{\prime} 17^{\prime \prime} \mathrm{S}, 43^{\circ} 46^{\prime} 23^{\prime \prime} \mathrm{W}, 680 \mathrm{~m}, 13 . \mathrm{III} .2009$, W. Milliken et al. 4086, fr. (SPF); Santana do Riacho: km 119 ao longo da Rodovia Belo Horizonte-Conceição do Mato Dentro, 15.XII.1980, I. Cordeiro et al. CFSC 6833, fl., fr. (SP, SPF, SPFR); idem: ca. 1-1,5 km NNE da pensão Chapéu-de-Sol (NNE Cardeal Mota), 1100-1200 m, 19॰17's, 4336'W, 21.IX.1990, G.L. Esteves et al. CFCR 15486, fl. (SPF); idem: km 115 ao longo da Rodovia Belo Horizonte-Conceição do
Mato Dentro, vale do córrego Andrequiçé (Indequicé), 8.XI.1980, A. Furlan et al. CFSC 6726, fl. (SP, SPF, SPFR, VIC); idem: $\mathrm{km} 104$ da MG-010, ca. $1,5 \mathrm{~km}$ da pousada Chapéu de Sol, 01.III.2001, M. Groppo et al. 635, fl. fr. (F, G, K, MBM, SPF); idem: distrito de Cardeal Motta, próximo a cachoeira dos Gaviões e da Farofa, $19^{\circ} 20^{\prime} 35^{\prime \prime S}, 43^{\circ} 35^{\prime} 15^{\prime \prime W}$, 24-27.IX.2002, L.S. Kinoshita et al. 02/182, fl. (SPFR, UEC); idem: trilha para a cachoeira da Farofa, na margem após o ribeirão das Pedras, $19^{\circ} 24^{\prime}$ 'S, $43^{\circ} 43^{\prime} \mathrm{W}$, 4.II.2007, E.G.A. Martins et al. 71, estéril (SPF, SPFR); idem: km 114 ao longo da Rodovia Belo Horizonte-Conceição do Mato Dentro, 19.XII.1979, J.R. Pirani \& M.C. Amaral CFSC 5872, bt., fl., fr. (SP, SPF, SPFR); idem: estrada da Usina, perto da ponte sobre o rio Capivara, 20.XII.1979, J.R. Pirani et al. CFSC 5918, fl., fr. (SP, SPF, SPFR); idem: vale do rio Cipó, $2 \mathrm{~km} \mathrm{E}$ da base do IBAMA para a serra das Bandeirinhas, $800 \mathrm{~m}$, 24.III.1991, J.R. Pirani et al. CFSC 11872, fr. (SPF, VIC).

Plenckia populnea é encontrada no Brasil em todas as grandes regiões, no Norte (Rondônia), Nordeste (Bahia), Centro-Oeste (Mato Grosso, Mato Grosso do Sul, Goiás e Distrito Federal), Sudeste (Minas Gerais e São Paulo) e Sul (Paraná), nos domínios fitogeográficos da Amazônia, Caatinga, Cerrado e Mata Atlântica, no cerrado lato sensu, na savana amazônica e na vegetação sobre afloramentos rochosos, como nos campos rupestres (Lombardi et al. 2015, Carvalho-Okano 1995), além de Florestas Estacionais Semideciduais (Groppo \& Pirani 2003). Ocorre também no Paraguai. Na Serra do Cipó é freqüente em manchas de cerrado e cerradões, ocorrendo também em matas ciliares, geralmente nas suas bordas. Ocorre também, mas mais raramente, em campos rupestres, atingindo, nesses casos, menor porte. Floresce em (abril) setembro a dezembro, com frutos até março, sendo espécie decídua na frutificação.

Plenckia populnea é uma espécie com grande variabilidade foliar, o que levou Reissek (1861) a reconhecer cinco variedades distintas, baseado no formato da lâmina. É reconhecida pelas folhas pendentes e serreadas ou crenadas, semelhantes aos álamos (Populus spp. - Salicaceae, daí o epíteto específico) das regiões temperadas do hemisfério norte. É muitas vezes referida pelo binômio Austroplenckia populnea (Reissek) Lundell, que, entretanto, é um nome ilegítimo.

\section{Pristimera Miers}

5.1. Pristimera celastroides (Kunth) A.C.Sm., Brittonia 3(3): 371. 1940.

Pristimera andina Miers, Trans. Linn. Soc. London 28: 364.1872

Material examinado: Santana do Pirapama, Serra do Cipó, acesso pelo vilarejo Inhame, margem do rio Cipó, acesso pela Fazenda Toucan Cipó, 1956 '42"S, 4350'17"W 635 m, 24.VII.2009, D.C Zappi 2223 \& N.P. Taylor, fl. (SPF).

Material adicional examinado: Paraná: Foz do Iguaçu, Parque Estadual do Iguaçu, estrada para o Poço Preto, 253' $30^{\prime \prime S}, 5^{\circ} 25^{\prime} 30^{\prime \prime W}, 180$ m, 2.X.2006, P.H. Labiak et al. 3758, fl. (SPF, UPCB). São Paulo: Ilha Solteira, Fazenda São José, 5.VIII.1995, M.R. Pereira-Noronha 1376, fl. (SPF); São 
Paulo, Cidade Jardim, 2.Il.1941, W. Hoehne s.n., fl. (BHCB, MBM, NY, SP, SPF 10825).

Espécie com ampla distribuição no Brasil, ocorrendo em todos os estados da Região Norte, no Nordeste (Bahia, Ceará, Maranhão, Paraíba, Pernambuco, Piauí e Rio Grande do Norte), no Centro-Oeste (Distrito Federal, Goiás e Mato Grosso), todos os estados da Região Sudeste e do Sul, nos domínios da Amazônia, Caatinga, Cerrado e Mata Atlântica (Lombardi et al.2015). Ocorre também no México, Guatemala, Bolívia, Paraguai e Argentina (Lombardi \& Lara 2003). Espécie de hábito lianescente, ocorre em áreas florestadas. Possui apenas um registro de coleta (Santana do Pirapama), em mata ciliar, com flores em junho.

Pristimera celastroides é a única espécie de "Hippocrateaceae" coletada na Serra do Cipó incluída na subfamília Hippocrateoideae, caracterizada pela posse de frutos esquizocárpicos com três mericarpos deiscentes; todas as outras espécies são da subfamília Salacioideae, com frutos drupas. A espécie em estado vegetativo e em frutificação é semelhante a Hippocratea volubilis L. (também Hippocrateoideae), de ampla distribuição no continente americano, do sul da Flórida até norte da Argentina (Lombardi \& Lara 2003), o que causa muitas vezes identificações errôneas em herbários.

Pristimera celastroides é mais conhecida na literatura pelo sinônimo $P$. andina Miers (e.g. Lombardi \& Lara 2003). Ilustrações em Lombardi \& Lara (2003).

\section{Salacia L.}

6.1. Salacia elliptica (Mart.ex Schult.) G. Don, Gen. Hist. 1: 628. 1831.

Material examinado: Minas Gerais, Santana do Riacho, Serra do Cipó, APA Morro da Pedreira, 19¹8'48,5"S, 4336'39,7"W, 1318 m, 24.IX.2007, M. Groppo et al. 1501, fl. (BHCB, SPF, SPFR).

Salacia elliptica ocorre na Venezuela, Colômbia, Guiana, Guiana Francesa, Equador, Peru, Bolívia, Paraguai e Brasil (Lara \& Lombardi 2003). No Brasil ocorre nos estados do Acre, Amazonas, Amapá, Pará, Rondônia, Roraima, Tocantins, Bahia, Maranhão, Pernambuco, Piauí, Distrito Federal, Goiás, Mato Grosso do Sul, Mato Grosso, Espírito Santo, Minas Gerais, Rio de Janeiro, São Paulo, Paraná e Santa Catarina, nos domínios fitogeográficos de Amazônia, Caatinga, Cerrado, Mata Atlântica e Pantanal (Lombardi et al. 2015). Foi coletada na forma de arbusto de 4-5 m de altura, com vários ramos eretos partindo de uma base comum no solo, com flores em novembro. Apenas um indivíduo foi avistado, ocorrendo na APA Morro da Pedreira (município de Santana do Riacho), em mata decídua sobre solo calcário.

\section{Tontelea Aubl.}

7.1. Tontelea micrantha (Mart. ex Schult.) A.C.Sm., Brittonia 3(3): 472. 1940.

Material examinado: Jaboticatubas, Parque Nacional da Serra do Cipó, trilha da base do IBAMA para o Capão dos Palmitos, 26.IX.1999, P. Fiaschi et al. 88, fl. (SPF); idem, trilha da Cachoeira da Farofa, próximo à sede do IBAMA, $19^{\circ} 22^{\prime} 46^{\prime \prime}$ S, 433'34,5”W, ca. 838 m, 22.IX.2007, M. Groppo et al. 1468, fl. (SPF, SPFR); Santana do Pirapama, Serra do Cipó, Vilarejo Inhame, trilha para o topo da Serra a partir da porteira azul nas estrada vilarejo-Fazenda Toucan Cipó, 16.XI.2007, L.M. Borges et al. 204, fl. (SPF); Santana do Riacho, Rodovia Belo Horizonte - Conceição do Mato Dentro, $\mathrm{km} 116$ (novo $\mathrm{km}$ 111), 24.VIII.1980, A. Furlan et al. CFSC6459, fl. (MBM, SP, SPF); idem, 5.X.1981, A. Furlan et al. CFSC7495, fl. (F, BHCB, HRCB, SP, SPF); idem, km 106 Rodovia Belo Horizonte - Conceição do Mato Dentro, 7.XI.1983, M. Venturelli et al. CFSC9163, fl. (BHCB, SPF); 3 $\mathrm{km}$ da cidade, Fazenda Bela Vista, 980 m, 17.II.1982, C.F. Muniz et al. CFSC7868, fr. (BHCB, HUEFS, SP, SPF); próximo à nascente do Véu de Noiva, 7.IX.1987, F.R.S. Pires et al. CFSC10458, fl. (BHCB, SPF).

Tontelea micrantha ocorre no Brasil na região Norte (Pará, Rondônia, Tocantins), Nordeste (Bahia, Pernambuco, Piauí), todos os estados da Região Centro-Oeste e Sudeste, além da região Sul (Paraná), nos domínios da Amazônia, Caatinga e Cerrado (Lombardi et al. 2015), ocorrendo também no Paraguai (Lombardi \& Lara 2003). Espécie de cerrado e de campos cerrados, ocorre nestas mesmas fisionomias na Serra do Cipó, na forma de arbusto até cerca de 1,5m; entretanto, em Borges et al. 204 (SPF) é referida como sendo árvore de $3 \mathrm{~m}$ de altura. Coletada com flores de agosto a novembro, com frutos (uma coleta) em fevereiro.

\section{Agradecimentos}

Os autores agradecem aos curadores dos herbários BHCB, ESA, HRCB, RB, SP, SPF e UEC pelo empréstimo de materiais e doação de exsicatas ao herbário SPFR; ao Departamento de Biologia da FFCLRP-USP (Ribeirão Preto) pela disponibilização de veículos para coletas; ao IBAMA pela disponibilização de alojamentos no Parque Nacional da Serra do Cipó; a Julio A. Lombardi pela confirmação das identificações das espécies de "Hippocrateaceae"; a Leonardo Biral pela discussão dos limites de algumas espécies e Paulo Margalho pelas ilustrações. O primeiro autor também agradece à Fapesp (processos 2006/07401-0, 2011/10446-0), à Pró-Reitoria de-Pesquisa da Universidade de São Paulo (Programa Pro-IP) e ao CNPq (bolsa de Produtividade em Pesquisa) pelo auxílio financeiro. 


\section{Referências}

APG (Angiosperm Phylogeny Group) 2009. An update of the Angiosperm Phylogeny Group classification for the orders and families of flowering plants: APG III. Bot. J. Linn. Soc. 161: 105-121.

BIRAL, L. \& J. A. LOMBARDI. 2013. A new species of Maytenus (Celastraceae) from Bahia, Brazil, and neotypification of Maytenus boaria. Harvard Pap. Bot. 18: 129-132.

BIRAL, L. \& LOMBARDI, J.A. 2014. Two new species and one new synonym of Maytenus (Celastraceae) from Brazil. Brittonia 66 (on-line first, DOI 10.1007/s12228-014-9339-z)

CARVALHO-OKANO, R. M. 1992. Estudos taxonômicos do gênero Maytenus Mol. emend. Mol. (Celastraceae) do Brasil extra-amazônico. Tese de doutorado. Universidade Estadual de Campinas.

CARVALHO-OKANO, R.M. 1995. Celastraceae. In B.L. Stannard (ed.) Flora of the Pico das AlmasBahia. Royal Botanic Gardens. Kew, p. 171-172.

CARVALHO-OKANO, R.M. 2000. Flora Fanerogâmica das Fontes do Ipiranga. 102 - Celastraceae. Hoehnea 27(1): 27-29.

CARVALHO-OKANO, R. 2005. Celastraceae. In M.G.L. Wanderley, G.J. Shepherd, T.S. Melhem, \& A.M. Giulietti (coords.) Flora Fanerogâmica do Estado de São Paulo. Vol 4. FAPESP-Rima. São Paulo, p. 185-194.

CARVALHO-OKANO, R.M. \& LEITÃO-FILHO, H.F. 2005. O gênero Maytenus Mol. emend. Mol. (Celastraceae) no Brasil extra-amazônico. In M.S. dos Reis \& S.R. Silva (eds.) Conservação e uso sustentado de plantas medicinais e Aromáticas: Maytenus spp. Espinheira Santa. IBAMA. Brasília, p. 11-52.

COUGHENOUR, J.M.; SIMMONS, M.P.; LOMBARDI, J.A. \& CAPPA, J.J. 2010. Phylogeny of Celastraceae subfamily Salacioideae and tribe Lophopetalae from morphological characters and nuclear and plastid genes. Syst. Bot. 35(2): 358367.

CRONQUIST, A. 1981. An integrated system of classification of flowering plants. Columbia University Press New York.

EDWIN, G. \& HOU, H. 1975. Celastraceae. In Flora of Panama (E. Woodson \& R.W. Schery, eds.). Ann. Missouri Bot. Gard. 62(1): 45-57.

FERREIRA, J.N., AQUINO, F.G., CARVALHOOKANO, R.M. \& PROENÇA, C.E.B. 2003. Celastraceae. In T.B. Cavalcanti \& A.E. Ramos (orgs.) Flora do Distrito Federal, Brasil. Vol. 3. Embrapa Recursos Genéticos e Biotecnologia. Brasília, p.141-149.
FURLAN, A. \& ARRAIS, M.G.M. 1989. Flora da Serra do Cipó, Minas Gerais: Hippocrateaceae. Bol. Bot. Univ. São Paulo 11: 99-103.

GIULIETTI, A.M.; MENEZES, N.L.; PIRANI, J.R.; MEGURO, M. \& WANDERLEY, M.G.L. 1987. Flora da Serra do Cipó, Minas Gerais: caracterização e lista das espécies. Bol. Bot. Univ. São Paulo 9: 1151.

GROPPO, M. 2005. Hippocrateaceae. In M.M.R.F. Melo \& F. Barros (org.) Flora Fanerogâmica da Ilha do Cardoso. Vol. 11. Instituto de Botânica. São Paulo, p. 145-147.

GROPPO, M. 2008. Flora Fanerogâmica do Parque Estadual da Serra do Brigadeiro: Celastraceae. Pabstia 19(3): 1-8.

GROPPO, M. 2009. Celastraceae. In M.M.R.F. Melo, F. Barros, M. Kirizawa, S.L. Jung-Mendaçolli, M.G.L. Wanderley (orgs.) Flora Fanerogâmica da Ilha do Cardoso. Vol. 14. Instituto de Botânica, São Paulo, p. 49-57.

GROPPO, M. \& PIRANI, J.R. 2003. Flora de GrãoMogol, Minas Gerais: Celastraceae. Bol. Bot. Univ. São Paulo 21(1): 163 - 165.

GROPPO, M.; SIMMONS, M.P.; CAPPA, J.J.; BIRAL, L. \& LOMBARDI, J.A. 2014. A new species of Maytenus (Celastraceae) with fleshy fruits from eastern Brazil, with notes on the delimitation of Maytenus. Syst. Bot. 39(2): 478-484.

HALLÉ, N. 1986. Celastraceae Hippocrateoideae. In P. Morat (ed.) Flore du Gabon. Vol. 29. Muséum National d'Histoire Naturelle. Paris, p. 1-287.

HEYWOOD, V. H. 1993. Flowering plants of the world. Oxford University Press. New York.

JOFFILLY, A. \& VIEIRA, R.C. 2006. Lectotypification of Goniodiscus elaeospermus and new synonyms for Maytenus (Celastroideae-Celastraceae) from Brazil. Kew Bull. 61: 265-267.

LOESENER, T. 1942. Celastraceae. In A. Engler \& K. Prantl. (eds.) Die natürlichen Pflanzenfamilien Ed. 2. Wilhelm Englemann. Leipzig, 20b, p. 87-197.

LOMBARDI, J.A. \& GRACIE, C. 2004 Hippocrateaceae. In N. Smith, S.A. Mori, A. Henderson, D. W. Stevenson \& S. V. Heald (eds.) Flowering plants of the Neotropics. Princeton University Press. New Jersey, p. 183-184.

LOMBARDI, J.A. \& GROPPO, M. 2010. Celastraceae. In R.C. Forzza et al. (eds.) Catálogo de plantas e fungos do Brasil. vol. 1. Jardim Botânico do Rio de Janeiro. Rio de Janeiro, p. 842-847.

LOMBARDI, J. A.; GROPPO, M. \& BIRAL, L.. 2015. Celastraceae. Lista de espécies da Flora do Brasil. Rio de Janeiro: Jardim Botânico do Rio de Janeiro. (disponível em http://floradobrasil.jbrj.gov.br/jabot/ floradobrasil/FB6786. Acesso em 19.Maio.2015. 
LOMBARDI, J.A. \& LARA, A.C.M. 2003. Hippocrateaceae. In M.G.L. Wanderley, G.J. Shepherd, T.S. Melhem, A.M. Giulietti \& M. Kirizawa (coords.) Flora Fanerogâmica do Estado de São Paulo. Vol. 3. FAPESP, RiMa. São Carlos, p. 109-122.

LUNDELL, C.L. 1939. Studies in American Celastraceae II. Notes on genera species from Mexico and South America. Lilloa 4: 377-387.

MABBERLEY, D. J. 1993. The plant-book: a portable dictionary of the higher plants. Cambridge University Press. Cambridge.

MCKENNA, M. J.; SIMMONS, M.P.; BACON, C.D. \& LOMBARDI, J.A. 2011. Delimitation of the segregate genera of Maytenus sensu lato (Celastraceae) based on morphological and molecular characters. Syst. Bot. 36: 922-932.

PIRANI, J.R. \& CARVALHO-OKANO, R.M. 1999. Maytenus rupestris (Celastraceae), a new species from Minas Gerais, Southeastern Brazil. Novon 9: 95-97.

REISSEK, S. 1861. Celastrineae. In C.F.P. Martius \& A.G. Eichler (eds.) Flora brasiliensis. Monachii. Frid. Fliescher, v. 11, pars 1, p. 1-36.

SIMMONS, M. P. 2004. Celastraceae. In K. Kubitzki (ed.) The families and genera of flowering plants. VI. Flowering plants. Dicotyledons. Celastrales, Oxalidales, Rosales, Cornales, Ericales. Springer. Berlin, p. 29-64.
SIMMONS, M.P. \& HEDIN, J.P. 1999. Relationships and morphological character change among genera of Celastraceae (including Hippocrateaceae). Ann. Missouri Bot. Gard. 86: 723-757.

SIMMONS, M.P.; SAVOLAINEN, V.; CLEVINGER, C.C.; ARCHER, R.H.; MATHEWS, S. \& DAVIS, J.I. 2000. Phylogeny of the Celastraceae inferred from morphology and nuclear and plastid loci. Amer. J. Bot. 87(6, suppl.): 156-157.

SIMMONS, M.P.; CLEVINGER, C.C.; SAVOLAINEN, V.; ARCHER, R.H.; MATHEWS, S. \& DOYLE J.J. 2001. Phylogeny of the Celastraceae inferred from phytochrome $B$ gene sequence and morphology. Amer. J. Bot. 88: 313-325.

STEYERMARK, J. A. 1988. Flora of Venezuelan Guayana - V. Ann. Missouri Bot. Gard. 75: 10581086.

THORNE, R. F. 1992. Classification and geography of the flowering plants. Bot. Rev. 58: 225-350.

THORNE, R.F. \& REVEAL, J.L. 2007. An updated classification of the Class Magnoliopsida ("Angiospermae"). Bot. Rev. 73(2): 67-182.

VIANA, R.A.G. \& VIEIRA, A.O.S. 2007. Flora arbórea da bacia do rio Tibagi (Paraná, Brasil): Celastrales sensu Cronquist. Acta Bot. Bras. 21 : 457-472 